\title{
Relation of BMI with Balance and Functional Mobility in College Students
}

Smriti ${ }^{* 1}$, Amandeep Singh ${ }^{2}$.

${ }^{* 1}$ Orthopaedics student, ASIMSR, Ludhiana, Baba Farid University of Health Sciences, Faridkot, Punjab, India.

${ }^{2}$ Assistant Professor, Department of Neurology, ASIMSR, Ludhiana, Baba Farid University of Health Sciences, Faridkot, Punjab, India.

\section{ABSTRACT}

Background: Overweight and obesity has been seen as a rising problem in India and around the world commonly in school and college going students at a very young age. The objective of the study is to find the relation of body mass index with balance and functional mobility and to enable the associated professionals to know better the consequences that can be caused by increase in the weight of an individual.

Methods: A total of 100 subjects (65 females and 35 males) were randomly recruited based on the inclusion and exclusion criteria. They were divided into 3 groups on the basis of their $\mathrm{Ml}$ as underweight, normal and overweight. Unilateral leg stand, tandem stand, sit to stand and timed up and go tests were assessed for each participant and the values were recorded.

Results: Results show that increase in weight has a positive relation with poor balance and functional mobility in college students. Individuals falling under underweight and normal BMI showed good test results that indicated good balance and mobility than compared to overweight individuals who had poorer results.

Conclusion: Increase in body mass index has a positive effect on balance and functional mobility as the population falling under overweight BMI had poorer values for balance and mobility tests as compared to the individuals who had underweight and normal BMI.

KEY WORDS: BMI, Balance, Functional mobility, College students.

Address for correspondence: Dr. Smriti. Orthopaedics student, ASIMSR, Ludhiana, Baba Farid University of Health Sciences, Faridkot, Punjab, India. E-Mail: madaik38@gmail.com

Access this Article online

Quick Response code

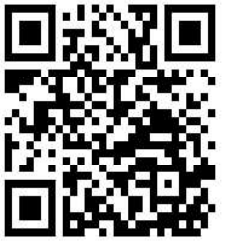

DOI: $10.16965 /$ ijpr.2021.162

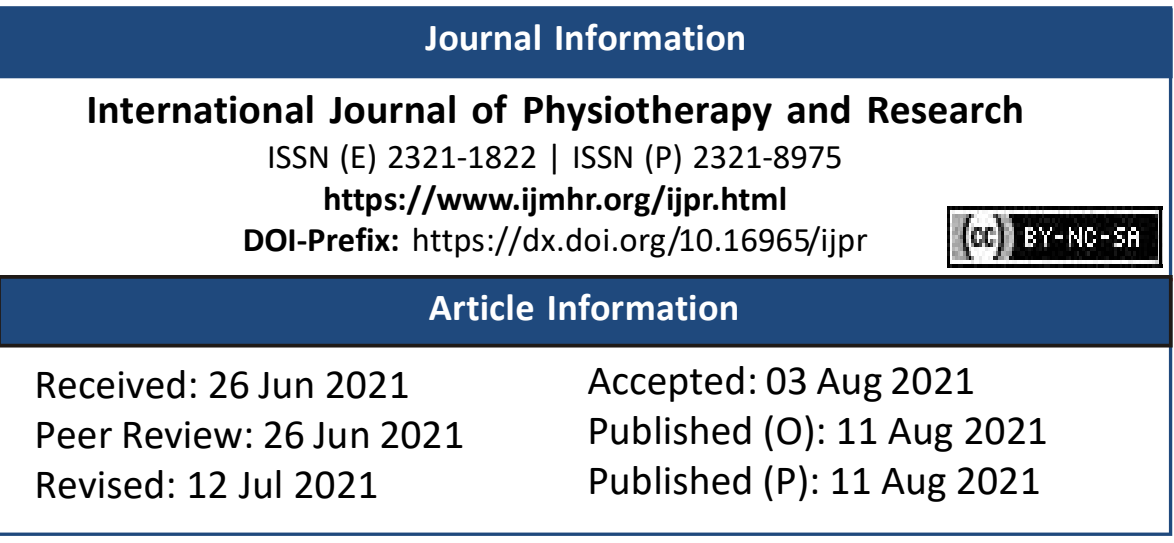

INTRODUCTION

Overweight and obesity has been seen as a rising problem in India and around the world commonly in school and college going students at a very young age [1]. Increase in weight is often neglected which leads to growth in number of people affected by obesity. This often leads to prevalence of non-communicable diseases further creating several socioeconomic issues acts as a burden to public health [2]. In India alone 14.4 million teens fall under the category of obesity and $5 \%$ of total population of the country is facing obesity [3].

Body mass index is the most widely and commonly used tool to classify weight in adults. Also known as Quetelet's index it is calculated by measuring height and weight of individuals in meters and kilograms respectively and dividing weight by height square. It has been stated as a reliable indicator of weight alterations in adults [4]. 
Bmi has been used as an easy and inexpensive tool that can be used by anybody. It is used for diagnosing obesity and overweight in individuals and further assisting in keeping a check on weight. Added benefit of using BMI is that in majority population once the height ceases only alterations are seen in the weight which causes change in the body mass index. Therefore, it is considered the best tool for keeping track of weight in individuals [5].

Balance is defined as the process that helps to maintain the centre of gravity of the body over the base of support [6].

Maintaining stable balance requires constant adjustments that are provided by positioning of the joints and regular muscular activity. Balance is also altered by musculoskeletal and nervous system diseases. To maintain postural balance requires sensory detection of body's movements, sensory motor integration in the central nervous system and appropriate motor response. Position of the body is guided by visual, vestibular and somatosensory functions [7]. Accumulation of adipose tissue and increase in body mass index can cause the decrease in balance and becomes contributing factor for falls and loss of stability [8].

Functional mobility is defined as the individuals are able to perform in the given environment so as to participate in the activities of daily living and to move around. These movements include walking, standing, climbing, bending etc. [9].

Several previous literatures suggest that high BMI has positive relation with disability and impairment of physical functioning leading to increased falls. Obesity has shown strong association with reduced mobility, increased falls and postural sway [10].

This information of relation of body mass index with balance and functional mobility will enable the associated professionals to know better the consequences of increased weight [11]. This relation would enable physical therapists in determining if it is necessary to give any alterations and measures for individuals who are obese [12].

In a scenario where obesity has become so prevalent, role of physiotherapists becomes an important part in this. Physical therapists being first line providers of health services have several roles to play in managing the health and needs of people facing obesity. To provide rehabilitation and manage individuals who are overweight or obese, physical therapists should learn to use and implement the weight reduction measures [13].

The study was necessary so as to find the co-relation of BMI with balance and functional mobility and to rule out the ways how health can be promoted in individuals by making them aware of their health and further decrease the risk of disability in young population. Also, this information would enable the health professionals to be more aware about the functional consequences of excess weight. This would also help to determine if it is necessary to alter the tests and measures for people with different BMI.

\section{METHODOLOGY}

The present study was carried out in Noida with a total of 100 participants (65 females and 35 males). The participants were divided into 3 groups based on their BMI as underweight, normal and overweight. Subjects who were aged between 18- 28 years, had BMI ranging from 16 to 30 , both males and females and with normal cognitive functions were selected. Additionally, subjects who had any neurological condition, musculoskeletal condition, lower extremity fractures, vertigo and involved in either yoga or gym were excluded from the study. Prior to the study each subject was informed about the procedure of the study and also a written informed consent was received.

Procedure: Each subject was made to perform 4 tests for the assessment of balance and functional mobility. Tests included for balance and mobility were the unilateral stance test, tandem stance test, timed up and go test and sit to stand test.

For unilateral leg stance, participants were made to stand in open space on clear floor and were asked to stand unassisted with one leg off the floor. Once the person was ready in comfortable position, the timer was started and the participant was asked to maintain the 
position for as long as he could. Time was stopped when person got tired or the leg that was off the ground touches the floor [14].

For tandem stance test participants were made to stand in an open area on clear floor. One foot was placed in front of the other with the heel of the foot touching toes of other foot. The participant was asked to maintain the position for as long as he could. Time was stopped when the person got tired or when he could not further maintain the position [15].

For Time up and go test, the participant started the test in a seated position. The patient was asked to stand from the chair, walk the distance of $3 \mathrm{~m}$ that was marked on the floor, turn, walk back to the chair and sit down. Time was stopped when the patient sits back [16].

For sit to stand test, participants were made to stand in front of a chair. The participant sits in the middle of chair with back straight and feet shoulder width apart to maintain balance and were instructed to sit and stand five times with the arms crossed and in front of the chest [17].

The values for each test were noted for every participant.

Table 1: Mean values of Population Demographics

\begin{tabular}{|c|c|c|}
\hline \multirow{3}{*}{ Total Subjects } & \multicolumn{2}{|c|}{ Mean } \\
\hline & \multicolumn{2}{|c|}{$N=100$} \\
\hline & Males $=35$ & Females $=65$ \\
\hline Age & \multicolumn{2}{|c|}{21.25} \\
\hline Height (centimeters) & \multicolumn{2}{|c|}{164.07} \\
\hline Weight (kilograms) & \multicolumn{2}{|c|}{60.24} \\
\hline BMI (kg/m^2) & \multicolumn{2}{|c|}{22.3} \\
\hline
\end{tabular}

The values for the tests were compared using Pearson correlation coefficient and $r$ value was calculated. To test the significance, the $P$ value was checked with $\mathrm{P}=0.05$. The result shows a significant relation in obese and normal population whereas the relation in non-significant for underweight and normal population.

Statistical Analysis: The statistics collected are presented as mean and standard deviation. The values for the tests were compared using Pearson correlation coefficient and $r$ value was calculated. To test the significance, the $P$ value was checked with $\mathrm{P}=0.05$ to find the relation of BMI with balance and functional mobility for the data.

\section{RESULTS}

\section{Unilateral Leg Stand}

Table 2: Relation of underweight with obese normal individuals.

\begin{tabular}{lccccc}
\hline \multicolumn{1}{c}{ BMI } & Mean & $\begin{array}{c}\text { Unilateral } \\
\text { leg stand }\end{array}$ & R value & P-value & $\begin{array}{c}\text { Significant } \\
\text { difference }\end{array}$ \\
\hline $\begin{array}{l}\text { Underweight, } \\
\text { Normal }\end{array}$ & 19.95 & 139 & 0.07 & $>0.05$ & $\begin{array}{c}\text { Non- } \\
\text { significant }\end{array}$ \\
Obese, Normal & 24.5 & 101.3 & 0.6 & $<0.05$ & Significant \\
\hline
\end{tabular}

The table 2 illustrates the relation of values of underweight and normal individuals with the values of obese and normal individuals for one leg stand test. Underweight and normal population have $P>.05$ and is non-significant whereas group of normal and overweight population have $P$ value $<.05$ which indicates significant results.

The results reveal that increased $\mathrm{BMI}$ makes unilateral leg stand values poorer in overweight individuals as compared to underweight and normal individuals who has good balance and mobility falling in normal ranges.

\section{Tandem Stance}

Table 3: Relation of underweight with obese normal individuals.

\begin{tabular}{lccccc}
\hline \multicolumn{1}{c}{ BMI } & Mean & $\begin{array}{c}\text { Tandem } \\
\text { Stance }\end{array}$ & R Value & P-Value & $\begin{array}{c}\text { Significant } \\
\text { Difference }\end{array}$ \\
\hline $\begin{array}{l}\text { Underweight, } \\
\text { Normal }\end{array}$ & 19.9 & 235.2 & 0.05 & $>0.05$ & $\begin{array}{c}\text { Non- } \\
\text { significant }\end{array}$ \\
\hline Obese, Normal & 24.5 & 157.1 & 0.58 & $<0.05$ & Significant \\
\hline
\end{tabular}

The table 3 illustrates the relation of values of underweight and normal individuals with the values of obese and normal individuals for tandem stand test. Underweight and normal population have $\mathrm{P}>.05$ and is non-significant whereas group of normal and overweight population have $P$ value $<.05$ which indicates significant results.

The results reveal that people with increased BMI had poorer test values for tandem stance as compared to underweight and normal population who had good balance and mobility falling in normal ranges.

\section{Sit To Stand}

Table 4 illustrates the relation of underweight and normal population and overweight and 
normal population for sit to stand test. Underweight and normal population have $P>.05$ and is non-significant whereas group of normal and overweight population have $P$ value $<.05$ which indicates significant results.

The results reveal that people with increased BMI had poorer test values for sit to stand test as compared to underweight and normal population who had good balance and mobility falling in the normal ranges.

Table 4: Relation of underweight with obese normal individuals.

\begin{tabular}{|cccccc|}
\hline BMI & Mean & Sit To Stand & R Value & P Value & $\begin{array}{c}\text { Significant } \\
\text { Difference }\end{array}$ \\
\hline $\begin{array}{c}\text { Underweight, } \\
\text { Normal }\end{array}$ & 19.9 & 11.9 & 0.24 & $>0.05$ & $\begin{array}{c}\text { Non- } \\
\text { significant }\end{array}$ \\
$\begin{array}{c}\text { Obese, Normal } \\
\text { Obese, }\end{array}$ & 24.5 & 10.2 & 0.56 & $<0.05$ & Significant \\
\hline
\end{tabular}

Timed Up and Go.

Table 5: Relation of underweight with obese normal individuals.

\begin{tabular}{lccccc}
\hline \multicolumn{1}{c}{ BMI } & Mean & $\begin{array}{c}\text { Time Up } \\
\text { and Go }\end{array}$ & R Value & P- Value & $\begin{array}{c}\text { Significant } \\
\text { Difference }\end{array}$ \\
\hline $\begin{array}{l}\text { Underweight, } \\
\text { Normal }\end{array}$ & 19.9 & 8.4 & 0.24 & $>0.05$ & $\begin{array}{c}\text { Non- } \\
\text { significant }\end{array}$ \\
$\begin{array}{l}\text { Obese, } \\
\text { Normal }\end{array}$ & 24.5 & 9.8 & 0.69 & $<0.05$ & Significant \\
\hline
\end{tabular}

Table 5 illustrates the relation of underweight and normal population and overweight and normal population for time up and go test. Underweight and normal population have $\mathrm{P}>.05$ and is non-significant whereas group of normal and overweight population have $P$ value $<.05$ which indicates significant results.

The results reveal that people with higher BMI had poorer test values for time up and go test as compared to underweight and normal individual who had good balance and mobility falling in normal ranges.

\section{DISCUSSION}

While examining balance and functional mobility in college going students altered results were found for the three groups of $\mathrm{BMI}$ - underweight, normal and overweight.

Population falling under underweight and normal BMI had similar results that were within the normal ranges of each test whereas normal and overweight population had values that were falling out of the normal ranges and showed reduced balance and functional mobility [18].
The observed relationship between balance and functional mobility indicated that as BMI of the individual increased, both balance and functional mobility became poorer.

For test 1 i.e. unilateral leg stand underweight and normal population showed good balance and functional mobility with the values falling over the normal range of more than 10 seconds. Both the groups had quiet similar results in respect to each other, whereas overweight and normal population had varied results that were noted as reduced number of seconds that affected their balance and functional mobility [19].

Similar pattern of results was noted for other three tests that were tandem stand, sit to stand and time up and go test where underweight and normal population had good balance and mobility with normal values of 30 seconds, 12 seconds and 12 seconds respectively. Overweight population had poorer test results that showed to hamper their balance and functional mobility [19].

Therefore, alteration in the test results for the three categories of BMI indicated high risk of impaired balance and functional mobility with increased BMI which could make these individuals more prone to falls and also make them fall prey to all the ill effects of increased weight in the near future [20].

Increased weight has also shown a relation with increased risk of developing certain diseases and decreased physical activity levels. Both these factors are considered to have negative relation with balance and functional mobility. Also, in the current study individuals who were overweight were less likely to engage into any sort of physical activity than compared to underweight and normal individuals [21].

Therefore, these individuals should be advised by their health care professionals to try and engage in more and more physical activity for the purpose of reducing the excess weight and reducing risk of disease or any impairments $[20,22]$.

The study had some limitations as well. Firstly, sample size of only 100 individuals was considered for the study and age group was 
restricted to 18 to 28 years. Also, study included a greater number of female subjects than the male subjects. The results might have been differed if the following limitations were altered.

\section{CONCLUSION}

The study concluded that increase in body mass index had a positive effect on balance and functional mobility as the population falling under overweight BMI had poorer values for balance and mobility tests where as individuals falling under underweight and normal BMI had normal test values which indicated good balance and functional mobility.

\section{ABBREVATIONS}

\section{BMI: Body Mass Index}

Funding: The study has no funding from any organization.

\section{Conflicts of interest: None}

\section{REFERENCES}

[1]. Sahoo K, Sahoo B, Choudhury AK, Sofi NY, Kumar R, Bhadoria AS. Childhood obesity: causes and consequences. J Family Med Prim Care. 2015 AprJun;4(2):187-92.

[2]. Thakur J, Prinja S, Garg CC, Mendis S, Menabde N. Social and Economic Implications of Noncommunicable diseases in India. Indian J Community Medicine. 2011 Dec;36(Suppl 1):S13-22.

[3]. Raj M, Kumar RK. Obesity in children \& adolescents. Indian Journal of Medical Research. 2010 Nov;132(5):598-607.

[4]. Garrow, J.S. \& Webster, J. Quetelet's index (W/H2) as a measure of fatness. International Journal of Obesity, 1985;9(2):147-153.

[5]. Nuttall FQ. Body Mass Index: Obesity, BMI, and Health: A Critical Review. Nutrition Today. 2015 May;50(3):117128.

[6]. Yiou E, Caderby T, Delafontaine A, Fourcade P, Honeine JL. Balance control during gait initiation: State-of-theart and research perspectives. World Journal of Orthopaedics. 2017 Nov 18;8(11):815-828.

[7]. Grace Gaerlan M, Alpert PT, Cross C, Louis M, Kowalski S. Postural balance in young adults: the role of visual, vestibular and somatosensory systems. J Am Acad Nurse Pract. 2012 Jun;24(6):375-81. doi: 10.1111/ j.1745-7599.2012.00699.x. Epub 2012 Mar 29. PMID: 22672489
[8]. Hill JO, Wyatt HR, Peters JC. Energy balance and obesity. Circulation. 2012 Jul 3;126(1):126-32.

[9]. Bouça-Machado R, Maetzler W, Ferreira JJ. What is Functional Mobility Applied to Parkinson's Disease? Journal of Parkinsons Disease. 2018;8(1):121-130.

[10]. Teasdale, N., Simoneau, M., Corbeil, P. Obesity Alters Balance and Movement Control. Current Obesity Reports,2013;2:235-240.

[11]. Hergenroeder AL, Wert DM, Hile ES, Studenski SA, Brach JS. Association of body mass index with self-report and performance-based measures of balance and mobility. Phys Ther. 2011 Aug;91(8):1223-34.

[12]. Janet R. Bezner, Promoting Health and Wellness: Implications for Physical Therapist Practice, Physical Therapy, 2015;95(10):1433-1444.

[13]. You L, Sadler G, Majumdar S, Burnett D, Evans C. Physiotherapists' perceptions of their role in the rehabilitation management of individuals with obesity. Physiotherapy Canada. 2012 Spring;64(2):168-75.

[14].Hunt MA, McManus FJ, Hinman RS, Bennell $\mathrm{KL}$. Predictors of single leg standing balance in individuals with medial knee osteoarthritis. Arthritis care \& research. 2010 Apr;62(4):496-500.

[15]. Hile ES, Brach JS, Perera S, Wert DM, VanSwearingen JM, Studenski SA. Interpreting the need for initial support to perform tandem stance tests of balance. Phys Ther. 2012 Oct;92(10):1316-28.

[16].Shumway-Cook A, Brauer S, Woollacott M. Predicting the probability for falls in community-dwelling older adults using the Timed Up \& Go Test. Physical therapy. 2000 Sep 1;80(9):896-903.

[17]. Rikli, R.E. and Jones, C.J. Development and validation of a functional fitness test for community-residing older adults. Journal of aging and physical activity,1999, 7(2),129-161.

[18]. Hergenroeder AL, Wert DM, Hile ES, Studenski SA, Brach JS. Association of body mass index with self-report and performance-based measures of balance and mobility. Phys Ther. 2011;91(8):1223-1234.

[19]. Deforche BI, Hills AP, Worringham CJ, Davies PS, Murphy AJ, Bouckaert JJ, De Bourdeaudhuij IM. Balance and postural skills in normal-weight and overweight prepubertal boys. Int J Pediatr Obes. 2009;4(3):175-82.

[20].Fjeldstad C, Fjeldstad AS, Acree LS, Nickel KJ, Gardner AW. The influence of obesity on falls and quality of life. Dyn Med. 2008;7:4.

[21]. Pi-Sunyer FX. Medical hazards of obesity. Ann Intern Med. 1993 Oct 1;119:655-60.

[22]. Zhu Y, Wang Q, Pang G, Lin L, Origasa H, Wang Y, Di J, Shi M, Fan C, Shi H. Association between Body Mass Index and Health-Related Quality of Life: The "Obesity Paradox" in 21,218 Adults of the Chinese General Population. 2015 Jun 18;10(6). ijpr.2021.162 